\title{
BMJ Global Health Towards constructive rethinking of PBF: perspectives of implementers in sub-Saharan Africa
}

\author{
Serge Mayaka Ma-Nitu, ${ }^{1}$ Lara Tembey, ${ }^{2}$ Eric Bigirimana, ${ }^{3}$ Christophe Y Dossouvi, ${ }^{4}$ \\ Olivier Basenya, ${ }^{5}$ Elizabeth Mago, ${ }^{6}$ Pacifique Mushagalusa Salongo, ${ }^{7}$ \\ Aloys Zongo, ${ }^{8}$ Fanen Verinumbe ${ }^{9}$
}

To cite: Mayaka Ma-Nitu S, Tembey L, Bigirimana E, et al. Towards constructive rethinking of PBF: perspectives of implementers in sub-Saharan Africa. BMJ Glob Health 2018;3:e001036. doi:10.1136/ bmjgh-2018-001036

Handling editor Seye Abimbola

Received 2 July 2018 Accepted 10 August 2018

\section{Sinked}

http://dx.doi.org/10.1136/ bmjgh-2017-000664

Check for updates

(C) Author(s) (or their employer(s)) 2018. Re-use permitted under CC BY-NC. No commercial re-use. See rights and permissions. Published by BMJ.

For numbered affiliations see end of article.

Correspondence to Professor Serge Mayaka MaNitu; sergemaya@yahoo.fr

\section{INTRODUCTION}

Performance Based Financing (PBF) is a health systems reform approach with an orientation on results defined in terms of the quantity and quality of services. PBF has rapidly gained popularity in many low/middle-income countries (LMIC), in Africa especially, as a strategy towards better health outcomes, strengthened health systems and progress towards Universal Health Coverage (UHC). The World Bank's Performance Based Financing Toolkit reports that in 2015 there were $34 \mathrm{PBF}$ schemes, at either pilot or national level, among the 51 countries of sub-Saharan Africa. ${ }^{1}$

The speed of PBF development raises concerns; recently Paul and colleagues ${ }^{2}$ took a critical position towards its implementation in LMICs and the results that it promises. The main areas of criticism include the availability of empirical evidence, the administrative costs of implementing a PBF programme and the sustainability of PBF programmes in the long run.

As experts directly involved in the implementation of PBF across Africa, we are keen to share our perspectives and experience and critically review the various contributions of PBF. We aim in this commentary to: (1) reflect on how the $\mathrm{PBF}$ approach has developed in Africa, particularly in the countries where we work-Burkina Faso, Burundi, Benin, Democratic Republic of Congo (DRC), Republic of Congo (Brazza) and Nigeria, (2) highlight how the PBF approach has benefited our health systems and informed transformations in the health sector, and (3) consider the challenges of and propose guidance for reforming PBF implementation.

\section{OUR OBSERVATIONS ON PBF AS A KNOWLEDGE AND POLICY PROCESS}

Our experiences as implementers of $\mathrm{PBF}$ show that every context and case is different.

\section{Summary box}

- As implementers of Performance Based Financing (PBF) in various countries in Africa, we have seen first-hand its benefits-but we acknowledge that there are challenges that require ongoing improvements, and that debates and critical analyses are opportunities to both question and strengthen the PBF approach.

- However, constructive debates must be based on facts, value the large set of experiences and require that all parties listen attentively and objectively to the arguments of stakeholders, especially those with local knowledge and diversified institutional affiliations.

- Notably, PBF was initiated in Rwanda, jointly by African and European experts-but we acknowledge that in our countries, PBF benefits from financial and technical leadership by the World Bank and other exogenous actors, and while exogeneity can raise problems, this is far from axiomatic.

- $\mathrm{PBF}$ is an evolving strategy, with innovation and amendments by national actors based on their context-in Democratic Republic of Congo (a tool for a fair sharing of bonuses), Rwanda (community verification), Cameroon (urban PBF), Burundi (exemption of user fees), Burkina Faso (focus on indigents), Nigeria (coupling PBF with demand-side financing approaches) and Zimbabwe (risk-based verification to reduce administrative costs).

- We see the value of PBF in its system-wide effects, such as improving coordination, decentralisation accountability and overall governance in the health system (including community engagement in health system governance), and completeness and timeliness of health information system data.

We alert the global health community against hasty conclusions drawn from a limited set of experiences or a biased review of the vast scientific and grey literature. We recognise that our perspectives are always partial and we value that many stakeholders have intimate knowledge of health systems strengthening issues. As such, 
we take different steps to overcome our knowledge gapsfor example, through sharing experiences within the PBF Community of Practice (CoP). We have contributed to the body of knowledge by sharing our experience through blogs, online discussions, trainings, workshops and sometimes as coauthors of research papers. As practitioners, we value greatly the knowledge generated by researchers, in its richness and possible contradictions. At the country level, we try to create the most welcoming conditions for rigorous studies and independent assessments of the PBF approach. We also do our best to follow the body of evidence and value lessons emerging from scientific work.

In their criticism of PBF in LMICs, Paul and colleagues framed its development as the work of some PBF champions motivated by direct and personal benefits, rather than as stemming from real national political will. ${ }^{2}$ We find this framing paternalistic. They emphasise the role of high-income country experts and obscure the contribution of LMIC experts, especially from Africa. Through their focus on the role played by international policy entrepreneurs, they overlook the national dynamics, the intricacies within the government apparatuses and the contributions of national actors. However, it is these national actors who are responsible for policy development, who seek to influence the process and implementation, who follow and correct it and ultimately benefit from $\mathrm{PBF} .{ }^{3} \mathrm{PBF}$ was theoretically and practically initiated in Rwanda, jointly by African and European experts. ${ }^{4}$ In more than 15 years of existence, the actual form of PBF in LMICs can be viewed as a cumulative process of experiences that took place in our different local contexts across sub-Saharan Africa.

The PBF approach has been improved by several African countries, with innovations coming from the DRC (a tool for a fair and transparent sharing of performance bonuses), Rwanda (community verification), ${ }^{5}$ Cameroon (household visits according to protocol and urban PBF) ${ }^{6}$ Burundi (coupling PBF with exemption of user fees) ${ }^{7-9}$ Burkina Faso (PBF with special focus on indigents, PBF with mutual health insurance), Nigeria (coupling PBF with demand-side financing approaches) and most recently Zimbabwe (riskbased verification to reduce administrative costs). Notably, DRC actors have also pioneered the application of the PBF approach to the education sector. ${ }^{10}$ To ignore all these African intellectual and programmatic contributions is just another variation of the mechanisms of misappropriation that is so often applied to Africa.

Research on the development of PBFatcountrylevelshould follow rigorous methodologies to identify these dynamics. For instance, using a health policy framework, such as Kingdon's multiple streams framework, ${ }^{11}$ and collecting primary data would have been beneficial for Paul $e t a l$ s analysis of the conditions of emergence in our countries. ${ }^{2}$ They would have appreciated the part that the 'problem stream' (the crises or failures observed in our health systems) played in this development at country level. There were windows of opportunity (in Kingdon's language), which helped advance the PBF policy. Even without primary data, a greater attention to the existing scientific literature ${ }^{12-14}$ would have usefully informed their analysis. Health policy analysis cannot be a practice of incorporation of convenient narrative elements and 'story telling': a comprehensive understanding of the complex realities of our countries is key; the donor-government relationship is only part of the story.

In some countries, such as Zimbabwe, Burundi and Cameroon, PBF is viewed by national actors as complementing already existing policies. In Zimbabwe, for instance, PBF is used as a tool to implement the Government's longstanding Results Based Management and Results Based Budgeting approach. ${ }^{15}$ The design of PBF in Zimbabwe was protracted because the Government placed a lot of emphasis on contextualising PBF principles within its health system and country context. The actors developed a PBF institutionalisation plan which laid out a road map for longterm implementation and governance arrangements while envisaging reduction in administrative and verification costs. This milestone saw an increase in budgetary allocation of US $\$ 5$ million each year (2013-2017) to US $\$ 10.2$ million with US\$58.1 million complemented by the Health Development Fund (2016-2020). The Health Development Fund was launched by the Government of Zimbabwe in partnership with the United Nations and other development partners, built on the achievements of two previous health sector programmes-the Health Transition Fund and Integrated Support Program - which aimed to strengthen the health system and scale up the implementation of high-impact health and nutrition interventions. PBF has evolved from a focus on different vertical programmes into the Zimbabwe Health Strategy of (2016-2020) and the UHC agenda. Integration into national processes also occurred in academiathe University of Zimbabwe now runs an international PBF course, which is practically designed for African contexts. ${ }^{16}$

However, we do not deny that PBF expansion benefited from the financial and technical leadership developed by the World Bank and other global health actors. ${ }^{17}$ But PBF is not the only strategy with such a partially exogenous origin-the Millennium Development Goals, the Sustainable Development Goals and the UHC agenda are all initiatives designed and promoted by external influences before they flourish in Africa. This does not make them inappropriate. ${ }^{18}$ We agree that any exogeneity can raise problems in terms of sustainability, but this is far from axiomatic.

\section{IMPLEMENTATION CHALLENGES}

The implementation of PBF, as with any other health reform strategy, is not without its challenges; more so in some countries than others. ${ }^{19-23}$ We therefore fully endorse the agenda of improving $\mathrm{PBF}$ and its implementation. When PBF evidence appears 'mixed', implementation research can be helpful in understanding the intricacies of these findings. A recent study conducted by Ogundeji $e t a t^{4}$ looked at how contextual and implementation factors influence the results of PBF in Nigeria. ${ }^{24}$ The study found that within scheme variation in performance can be explained by health worker's understanding of PBF, effective communication between the regulator and the 
provider and uncertainty in earning the incentive. We must try to understand heterogeneity in results with the aim of improving both design and implementation. We appreciate the recent attempts to understand the specific context that may enable or hinder the PBF implementation and effectiveness. ${ }^{25} 26$

PBF practitioners are, for instance, well aware that verification costs are too high in some programmes: they were directly involved in the documentation of the problem. ${ }^{27}$ Experts affiliated to the PBF CoP have set up a working group and are assisting countries to learn from each other $^{28}$ and move forward this agenda. ${ }^{29}$ Through this deliberative process, good practices are emerging, notably, the need to gradually transition from intensified verifications during first years of implementation to risk-based verification mechanisms in later years. Such a transition has led to a reduction in verification costs in Zimbabwe by $47 \% .^{15}$ PBF programmes are not static but continue through action research ${ }^{30}$ to seek the best possible strategy towards improving the health system.

Another critical assumption is that health facilities become dependent on financial incentives and may cease to function if there are any delays to these payments. Although we acknowledge that this has occurred in some instances, we find that the fact that PBF introduces decentralisation, challenges input monopolies and gives autonomy at the level of the health facility is often incentive enough to improve health facility performance. For example, in Cameroon there have been regular delays in payments to health facilities of up to 6 months at times. However, even without this regular financial incentivisation, the results of the health facilities improved greatly; the facilities did not stop work, implying that there are other forces that play a role in incentivising the facilities. ${ }^{31}$

One of the major challenges mentioned in many papers that discuss PBF is the lack of sustainability of programmes in the long run. As implementers, we have faced challenges regarding the sustainability of $\mathrm{PBF}$ in some countries, particularly as it moves from project to programme mode. Solutions to ensure that PBF transcends from a project to a programme-based system are context bound and therefore differ from country to country. ${ }^{12}$ However, they are similar in observing the importance of key financing mechanisms and establishing sustainable machinery to operationalise the approach. For example, in Zimbabwe, the coordination framework of PBF is built on existing structures at the district and national level to promote multistakeholder collaboration of District Health executive, local government, facility representatives and local purchasing units from Cordaid. ${ }^{15}$

In our experience, positioning of the PBF Unit is vital to the sustainability and government ownership of PBF and ultimately systemic change in the health sector and beyond. In countries such as the Central African Republic (CAR), Cameroon, Burundi, Zimbabwe and Rwanda where the $\mathrm{PBF}$ Unit is positioned at a level where it is able to effectively coordinate the health sector activities, there has not been an issue of government participation and ownership, and often there has been a full move towards national policy for PBF. To some extent, the experience of Benin cited by Paul and colleagues ${ }^{2}$ is an example of what not to do: that is, postpone the creation of such a national unit and allow two projects to coexist and undermine each other.

In short, we see PBF as a flexible approach that has evolved over time. PBF programmes are evaluated through impact and qualitative studies as well as action research, which have led to a corpus of good practices. It is a constant evolution. For example, a recent mid-term review of PBF in Nigeria has led to the identification of implementation bottlenecks, once again resulting in changes to the PBF design. This transformational mode is the name of the game.

\section{PBF AND THE STRENGTHENING OF HEALTH SYSTEMS}

As health system actors, we observe and value several important systemic effects which are observable in the health systems dynamics, and at different levels of the system. We will illustrate this by looking at four of those effects on health system governance.

First, the establishment of national PBF steering committees has brought together decision-makers at the national level, technical and financial partners and various sectoral managers. These PBF steering committees have increased the sharing of information and strengthened the culture of decision-making based on evidence at the central level. Almost all countries adopting PBF are moving in this direction to improve stakeholder engagement for better information sharing on implementation.

Second, at the intermediate level: provincial/regional management teams and district management teams are contracted to provide supervision and monitoring of implementation, which further empowers these regulatory actors. ${ }^{32}$ By introducing district validation committees, who play a key role in the validation of the monthly/quarterly invoices, district-level actors regularly coordinate health activities at the local level.

Third, at the level of the healthcare provider, the introduction of tools such as the business plan and the indices management tools has increased transparency in management and accountability among health workers of a health facility, ${ }^{1}$ and now even among the various stakeholders in the PBF programme (regulatory authorities, contract development and verification agencies).

Fourth, PBF strives to bring together groups of community representatives to strengthen collaboration between healthcare providers and surrounding communities. Through community satisfaction surveys conducted by local community-based organisations, patients of the facilities have a voice to give honest feedback around the quality and affordability of service that they receive; holding the facilities accountable for the service that they provide. ${ }^{9}$

In addition to governance, PBF contributes to improving the completeness and timeliness of health information system data. PBF quality checklists have generated a wealth of data on their actual nature of the services delivered to the 
population. Today, with the development of DHIS2, interoperability between DHIS2 and PBF databases is realised or under development in many countries (DRC, Central African Republic, Congo, Côte d'Ivoire, Burundi, Nigeria). This interoperability allows alignment of PBF indicator definitions with national health information system definitions. Criticisms on this aspect were valid a few years ago, but not anymore. This convergence between data systems is an example of how actors identify shortcomings, progressively improve PBF implementation and take advantage of new opportunities such as the huge development of information and communication technologies. Indeed, PBF can be a major accelerator of the digitalisation of our health systems.

The systemic effects of PBF can and does reach beyond the health system. PBF is also a proposition to change practices in the aid and public sectors. ${ }^{33}$ One of the radical propositions put forward by PBF is that funding should directly reach health facilities (without intermediaries), thus guaranteeing their greater control on the delivery of services to the population. We sincerely hope that this will be the future standard, both for aid agencies and our governments. One potential effect of this principle is to link this funding to the achievement of measurable and verifiable specific results. This would be a systemic change in terms of accountability for our countries (which are often overcentralised, with weak governance), and for the aid industry (as sometimes, an unacceptable proportion of aid return to the donor country through its implementing agencies).

Thanks to PBF, we have been able to highlight the central role of institutional arrangements for the improved performance of our health systems. ${ }^{34}{ }^{35}$ It has put issues such as the importance of clarifying the mission of different components of the health system squarely on the agenda, and of better aligning incentives to those missions, through provider payment reforms. ${ }^{36}$

PBF is not an end in itself and is bound to evolve. It has set countries on new pathways and will allow further transformation of our health systems, such as making the purchasing for UHC more strategic. ${ }^{37}$ Certainly, there is still a lot to document, prove and discover with respect to the multiple system effects of PBF, but from the evidence we see emerging at the implementation level, $\mathrm{PBF}$ is bringing much needed positive change to our health systems.

\section{RETHINKING PBF}

Let's be clear: as experts, we subscribe to the agenda of updating the PBF approach. And this revision process is already taking place in some countries, with real control by national actors. ${ }^{38}$ As shown by different collective dynamics, particularly within the PBF CoP, but also at the level of the research community, ${ }^{39}$ the rethinking of PBF is already under way. For instance, rethinking is already launched on the challenge of measuring quality of care and the exact contribution of PBF in its improvement. Experts from diverse backgrounds, African and non-African, some working on PBF and others with an expertise in another domain (eg, family planning) are contributing in this area. ${ }^{40}$
But we agree that more could be done in different aspects of the approach. ${ }^{25}$ We must move faster in this critical review. The growing body of empirical studies can help question some 'dogmas'. We must certainly also allow more variation in terms of designs and implementation. ${ }^{27}$ Critical review by external observers can really be helpful for this agenda, if the intention is constructive.

We believe that a synthesis is possible, if we make a common effort to better structure convergences and divergences. Mayaka et al showed that a consensus was possible around the consideration of $\mathrm{PBF}$ as a lever for change and a complementary strategy to other strategies, for example, those focused on improving financial access to health services (ie, vouchers for selective free healthcare) ${ }^{41}{ }^{42}$ However, this synthesis will only be possible if we do not force actors to position themselves as 'proponents' or 'opponents' of PBF. This polarisation, actually often exogenous to our countries, slows down the synthesis which mobilises country experts. The worst thing for our countries would be to be left in an 'in-between situation' which would create uncertainty and in fact perpetuate an eternal dependence on the development aid fads denounced by Paul and colleagues. ${ }^{2}$

\section{CONCLUSION}

As implementers, we have witnessed a range of effects of $\mathrm{PBF}$ in our health sectors, some challenging, and some positive as highlighted in this paper. As a global health community, we can help PBF to continue to evolve. This is what implementation is all about: constantly balancing, constantly adapting to new circumstances. There is no room for complacency: our prime concern should be the strengthening of our health systems for the greater benefit of the population. We are committed to playing an important role both at country and at global level to continually update the PBF approach as we learn lessons from implementation.

\section{Author affiliations}

${ }^{1}$ Department of Management and Health Policy, Public Health School of Kinshasa, Kinshasa, Democratic Republic of Congo

${ }^{2}$ Nigeria State Health Investment Project (NSHIP) Project Implementation Unit, National Primary Health Care Development Agency, Abuja, Nigeria

${ }^{3}$ BREGMANS Consulting \& Research, Bujumbura, Burundi

${ }^{4}$ Health System Strengthening for Better Maternal and Child Health Results Project, Brazzaville, Republic of Congo

${ }^{5}$ PBF National Technical Unit, Ministry of Public Health and Fight Against AIDS, Bujumbura, Burundi

${ }^{6}$ National Nutrition Agency, Banjul, The Gambia

${ }^{7}$ PBF National Technical Unit, Health System Strengthening for Better Maternal and Child Health Results Project, Kinshasa, Democratic Republic of Congo

${ }^{8}$ Ministry of Health/RBF Program, Ouagadougou, Burkina Faso

${ }^{9}$ Nigeria State Health Investment Project (NSHIP) Project Implementation Unit, National Primary Health Care Development Agency, Abuja, Nigeria

Contributors As the lead author, I confirm that all coauthors contributed to the writing of this article and that they agree to this publication.

Competing interests None declared.

Patient consent Not required.

Provenance and peer review Not commissioned; internally peer reviewed.

Data sharing statement № additional data are available.

Open access This is an open access article distributed in accordance with the Creative Commons Attribution Non Commercial (CC BY-NC 4.0) license, which 
permits others to distribute, remix, adapt, build upon this work non-commercially, and license their derivative works on different terms, provided the original work is properly cited and the use is non-commercial. See: http://creativecommons.org/ licenses/by-nc/4.0

\section{REFERENCES}

1. Fritsche G, Soeters R, Meessen B. Performance-based financing toolkit. Washington, DC: World Bank, 2014.

2. Paul E, Albert L, Bisala BN, et al. Performance-based financing in low-income and middle-income countries: isn't it time for a rethink? BMJ Glob Health 2018;3:e000664.

3. Walt G, Gilson L. Reforming the health sector in developing countries: the central role of policy analysis. Health Policy Plan 1994;9:353-70.

4. Meessen B, Musango L, Kashala JP, et al. Reviewing institutions of rural health centres: the Performance Initiative in Butare, Rwanda. Trop Med Int Health 2006;11:1303-17.

5. Renaud A, Semasaka JP, 2014. Rwanda: verification of performance in cVerification of Performance in Community RBF. Health, Nutrition and population global practice knowledge butrition and population global practice knowledge brief; World Bank, Washington, DC. World Bank. https://openknowledge.worldbank.org/handle/10986/25127

6. Zang O, Djienouassi S, Sorgho G. 2015.Impact of performance based financing on health-carequality and utilization in urban areas of Cameroon. African health monitor 2015. issue 20: special issue on universal health coverage. http://www.aho.afro.who.int/sites/default/ files/ahm/reports/4366/ahm-20-02-impact-performancebasedbased-financing-health-care-quality.pdf

7. Basenya O, Nimpagaritse M, Busogoro F. 2011;5.Le Financement basé sur la performance comme stratégie pour améliorer la mise en oeuvre de la gratuité des soins: premières leçons de l'expérience du Burundi. PBF CoPWorking Paper. http://www.multicountrypbfn etwork.org/artiburundi.pdf

8. Bonfrer I, Van de Poel E, Van Doorslaer E. The effects of performance incentives on the utilization and quality of maternal and child care in Burundi. Soc Sci Med 2014;123:96-104.

9. Falisse JB, Ndayishimiye J, Kamenyero V, et al. Performance-based financing in the context of selective free health-care: an evaluation of its effects on the use of primary health-care services in Burund using routine data. Health Policy Plan 2015;30:1251-60.

10. Mushagalusa P, Ntabuyantwa C, Vroeg P. 2012.Le Financement basé sur la Performance dans le Secteur de l'Education : expérience pilote de Shabunda Sud Kivu en RDC. CoPWorking Paper Series. http://www.healthfinancingafrica.org/uploads/8/0/8/8/8088846/wp7. $\mathrm{pd}$

11. Kingdon JWA. Alternatives, and public policies. 2nd edn. New York: Longman, 2003:273.

12. Kiendrébéogo JA, Shroff ZC, Berthé A, et al. Why performancebased financing in chad failed to emerge on the National Policy Agenda. Health Systems \& Reform 2017;3:80-90.

13. Shroff ZS. Bigdeli M \&MeessenB. From scheme to system (Part 2): findings from ten countries on the policy evolution of resultsbased financing in health systems. Health Systems \& Reform 2017;3:137-47.

14. Sieleunou I, Turcotte-Tremblay AM, Fotso JT, et al. Setting performance-based financing in the health sector agenda: a case study in Cameroon. Global Health 2017;13:52

15. Oranje M. 2018. Towards a more balanced rethinking of performance-based financing. Blog on BMJ Global Health, Posted on February 9. http://blogs.bmj.com/bmjgh/2018/02/09/towards-amore-balanced-rethinking-of-performance-based-financing/

16. Moyo I, Gandidzanwa C, Tsikira T. 2016.Learning from implementation: process monitoring and evaluation II of Zimbabwe's Results-Based Financing Project (the case of Mutoko, Chiredszi, Nkayi and Kariba districts). Zimbabwe. https://www.rbfhealth. org/resource/learning-implementation-process-monitoring-andevaluation-ii-zimbabwe\%E2\%80\%99s-results-based

17. Gautier L, Tosun J, De Allegri M, et al. How do diffusion entrepreneurs spread policies? Insights from performance-based financing in Sub-Saharan Africa. World Dev 2018;110:160-75.

18. Basinga P, Mayaka S, Condo J. Performance-based financing: the need for more research. Bull World Health Organ 2011;89:698-9.

19. Van de LooijF. MD, Sisimayi C. 2018. Early evidence from resultsbased financing in rural Zimbabwe. African health monitor 2015. issue 20: special issue on universal health coverage. http://www.aho.afro.who. int/sites/default/files/ahm/reports/4386/ahm-20-06-early-evidenceresults-based-financing-rural-zimbabwe.pdf
20. Bonfrer I, Soeters R, Van de Poel E, et al. Introduction of performance-based financing in burundi was associated with improvements in care and quality. Health Aff 2014;33:2179-87.

21. Janssen W, Ngirabega JD, Matungwa M, et al. Improving quality through performance-based financing in district hospitals in Rwanda between 2006 and 2010: a 5-year experience. Trop Doct 2015;45:27-35

22. Steenland M, Robyn PJ, Compaore P, et al. Performance-based financing to increase utilization of maternal health services: Evidence from Burkina Faso. SSM Popul Health 2017;3:179-84.

23. Bank W. Plan Nacer: health insurance for the poor in Argentina results-based financing secures health insurance and services for the poor. IBRD results. Washington, DC: World Bank Group, 2010.

24. Ogundeji YK, Jackson $C$, Sheldon $T$, et al. Pay for performance in Nigeria: the influence of context and implementation on results. Health Policy Plan 2016;31:955-63.

25. De Allegri M, Bertone MP, McMahon S, et al. Unraveling PBF effects beyond impact evaluation: results from a qualitative study in Cameroon. BMJ Glob Health 2018;3:e000693.

26. Bertone MP, Falisse JB, Russo G, et al. Context matters (but how and why?) hypothesis-led literature review of performance based financing in fragile and conflict-affected health systems. PLoS One 2018;13:e0195301.

27. Antony M, Bertone MP, Barthes O. Exploring implementation practices in results-based financing: the case of the verification in Benin. BMC Health Serv Res 2017;17:204

28. Josephson E. 2017.Verification of results: the experience of Zimbabwe. Blog in health financing in Africa. http://www.healthfi nancingafrica.org/home/verification-the-experience-of-zimbabwe

29. Josephson E, Zongo A, Mecaskey J. 2018.Verification in PBF - the way forward for low- and lower-middle income countries. Blog in health financing in Africa. http://www.healthfinancingafrica.org/ home/verification-in-pbf-the-way-forward-for-low-and-lower-middleincome-countries

30. Bertone MP, Jacobs E, Toonen J, et al. Performance-based financing in three humanitarian settings: principles and pragmatism. Confl Health 2018;12:28.

31. deWalque D, Robyn PJ, Saidou H. Looking into the performancebased financing black box evidence from an impact evaluation in the health sector in Cameroon. Policy research working paper no. WPS 8162. Washington, DC: World Bank, 2017.

32. Kahindo JB, Meessen B, Byamungu T. 2011.Contrat de performance avec une administration sanitaire provinciale: cas du Nord Kivu en République Démocratique du Congo. PBF CoP Working Paper Series. https://orbi.uliege.be/bitstream/2268/202956/1/Porignon PBFAdminProv_NK_Kahindo_2011.pdf

33. Meessen B, Soucat A, Sekabaraga C. Performance-based financing: just a donor fad or a catalyst towards comprehensive health-care reform? Bull World Health Organ 2011;89:153-6.

34. Soeters R, Habineza C, Peerenboom PB. Performance-based financing and changing the district health system: experience from Rwanda. Bull World Health Organ 2006;84:884-9.

35. Meessen B, Van Damme W. Systèmes de santé des pays faible revenu : vers une révision des configurations institutionnelles? Mondes en Développement 2005;33:59-73.

36. Bertone MP, Meessen B. Studying the link between institutions and health system performance: a framework and an illustration with the analysis of two performance-based financing schemes in Burundi. Health Policy Plan 2013;28:847-57.

37. Soucat A, Dale E, Mathauer I, et al. Pay-for-Performance debate: not seeing the forest for the trees. Health Systems \& Reform 2017;3:74-9.

38. Basenya O. 2018.Financement Basé sur la Performance: ne pas jeter le bébé avec l'eau du bain !Blog in health financing in Africa. http://www.healthfinancingafrica.org/home/financement-base-sur-laperformance-ne-pas-jeter-le-bebe-avec-leau-du-bain

39. Renmans D, Holvoet N, Criel B, et al. Performance-based financing: the same is different. Health Policy Plan 2017;32:860-8.

40. Uzamukunda C. 2017.PBF \& Family Planning Meeting: a participant perspective. Blog in health financing in Africa. http://www.healthf nancingafrica.org/home/pbf-family-planning-meeting-a-participantperspective

41. Mayaka Manitu S, Muvudi Lushimba M, Macq J, et al. Arbitrage d'une controverse de politique de santé : application d'une démarche délibérative au Financement basé sur la Performance en Afrique subsaharienne. Santé Publique 2015;27:425-34

42. Mayaka Manitu S, Meessen B, Muvudi Lushimba M, et al. Le débat autour du financement basé sur la performance en Afrique subsaharienne: analyse de la nature des tensions. Santé Publique 2015;27:117-28. 